\title{
The Perceived Advantages and Disadvantages of Presymptomatic Testing for Machado-Joseph Disease: Development of a New Self-Response Inventory 1
}

\author{
Luísa Rolim, ${ }^{2,5}$ José A. Zagalo-Cardoso, ${ }^{3}$ Constança Paúl, ${ }^{4}$ \\ Jorge Sequeiros, ${ }^{2,4}$ and Manuela Fleming,
}

\begin{abstract}
Published Online: 27 September 2006
This study describes the construction of a self-response inventory to evaluate the perception of advantages and disadvantages of the Machado-Joseph disease presymptomatic testing, in 44 individuals at-risk for this disease. The results showed that the reliability of this inventory was satisfactory. Factor analysis revealed a bidimensional structure: perceived advantages (pros) and perceived disadvantages (cons) of presymptomatic testing. Social desirability was found unrelated to the total scores of our inventory. Additional correlation studies, with other scales, confirmed the convergent validity of the instrument. These results suggest adequate construct validity. This inventory thus seems to be a proper instrument to assess expectations involved in the decision-making process of Machado-Joseph disease presymptomatic testing.
\end{abstract}

KEY WORDS: Machado-Joseph disease; presymptomatic testing; perceived advantages/disadvantages; self-response inventory; decision-making process

\section{INTRODUCTION}

\section{Machado-Joseph Disease and Presymptomatic Testing}

Machado-Joseph disease (MJD) was first described in the United States, by Nakano et al. (1972).

\footnotetext{
${ }^{1}$ This article is based on the master thesis of Luísa Rolim and some portions were presented at the European Meeting on Psychosocial Aspects of Genetics (June 12-15, 2004) in Munich, Germany. CGPP, IBMC (JS) is a partner of EuroGentest-Genetic Testing in Europe (www.eurogentest.org) and of PHGEN-Public Health Genomics Network (www.phgen.nrw.de).

${ }^{2}$ Centro de Genética Preditiva e Preventiva (CGPP), Institute for Molecular and Cell Biology (IBMC), University of Porto, Campo Alegre, 823, 4150-180, Porto, Portugal.

3 Psychology and Sciences of Education College, University of Coimbra, Coimbra, Portugal.

${ }^{4}$ ICBAS, University of Porto, Porto, Portugal.

${ }^{5}$ Correspondence should be directed to Luísa Rolim, Centro de Genética Preditiva e Preventiva (CGPP), Institute for Molecular
}

Although it predominantly affects people of Azorean ancestry, in Portugal, the U.S.A. and Canada (Sequeiros, 1995) it has also been described in nonPortuguese families. Owing, mainly, to the involvement and interest of the International Joseph Disease Foundation, which organized a large number of genetic screening sessions, several non-Portuguese families have been located in Northern America, coming from Costa Rica, Russia, Italy, France and China. An English family living in Rhode Island has also been identified more recently (Coutinho, 1994).

MJD is one of the spino-cerebellar ataxias (SCAs), also known as SCA3, with an autosomal dominant inheritance, and is considered a cerebellar ataxia, affecting postural balance and the coordination of all movements, including gait, speech and

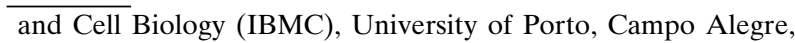
823, 4150-180, Porto, Portugal; e-mail: lrolim@ufp.pt. 
the fine movements of hands. It is progressive and appears late in life, at an average age of 40.2 years (43.7 years for women and 37.3 years for men). The MJD clinical picture includes other manifestations such as oculomotor problems and bulging eyes, fasciculations, peripheral muscular atrophies and dystonia (a tendency for abnormal postures and some torsion movements). There is neither mental deterioration nor loss in sphincter control. To date, unfortunately, we know of no clinical interventions to prevent or delay the appearance of the disease. This disease is now well known as the most prevalent SCA worldwide.

MJD is due to the expansion of a CAG repeat, similar to Huntington disease (HD), within the coding region of MJD/ATXN3 gene on chromosome 14q32.1 (Kawaguchi et al., 1994). Since 1995, direct detection of the genetic mutation responsible for MJD has been possible allowing for reliable presymptomatic diagnosis (Sequeiros, 1996a).

Preliminary studies have investigated attitudinal, psychosocial, and demographic factors that may, or may not, predict the decision to be tested for a late onset neurogenetic disease, such as HD (e.g., Bloch et al., 1989; Decruyenaere et al., 1993, 1997; Evers-Kiebooms and Decruyenaere, 1998; Jacopini et al., 1992; Meissen et al., 1988; van der Steenstraten et al., 1994). As outlined by these studies, a host of socio-demographic (e.g., gender, marital status, educational level, socio-economic status) and psychological (e.g., coping style, ego strength, emotional well-being, risk perception, perceived severity of the condition, perceived benefits and costs of the health action) variables have been identified as influencing the decision, or at least the intention, to have a predictive genetic testing.

The domain of genetic testing is an interesting one from a health decision-making viewpoint, because the behavior under consideration is by definition a detection behavior, as opposed to a behavior with a more causal link (either health promoting or impairing) like diet, exercise, smoking, etc. Thus, examination of decision-making strategies and predictors, including perceived advantages/disadvantages, relevant to genetic testing, is of potential interest.

\section{Previous Research on Presymptomatic Testing for MJD}

In order to explore the factors associated with the decision to undergo presymptomatic testing for
MJD, a number of authors (Paúl, 1996, 1997; Paúl et al., 2000; Rolim, 2000) have been developing psychological evaluation instruments, and exploring potential predictors of genetic testing uptake, such as certain aspects of personality, attitudes towards marriage, children, adoption and abortion, and the perception of costs and benefits of genetic testing, which we will explore in detail, as the purpose of our study was to develop a measure of pros/cons perceptions about MJD genetic testing.

From the psychological point of view, the benefits of having MJD presymptomatic testing were found to be a reduction in the degree of uncertainty (independently of test result) and the possibility for planning the future with regard to procreation and the disease itself (Sequeiros, 1995, 1996a). Other advantages of presymptomatic testing for this disease have been mentioned, by at-risk individuals, namely to reduce anxiety (obtain reassurance), inform children about the risk of developing the disease or even the possibility of beginning medical treatment (yet inexistent) for the disease in order to prevent its development and/or delay its course (Rolim, 2000). The arguments mentioned against presymptomatic testing for MJD were the anticipation of negative consequences (e.g., emotional consequences in the family, in the peer group and the affected individual) from a carrier result, and the individual's difficulties in adapting to this outcome.

\section{National Program of Presymptomatic Testing}

In Portugal, MJD presymptomatic testing is offered as part of a program (National Program of Presymptomatic Testing and Genetic Counseling in $\mathrm{MJD}^{6}$ ) to asymptomatic adults who would like to be informed about their genetic status. Figure 1 shows the current MJD presymptomatic testing protocol (Sequeiros, 1996b) implemented both in our centre (CGPP) and in other regional centers. This protocol reflects an integrated, multi-disciplinary, multiphased process, with several sessions organized

\footnotetext{
${ }^{6}$ The National Program of Presymptomatic Testing and Genetic Counseling in MJD was approved in 1995 and it began being implemented in January 1996. Along this first year, it was promoted the formation of national centers and the constitution of the respective teams as well as the elaboration of the consultation protocol. Still in the same year (1996) consultations had their beginning, as defined by the protocol, in four of the six centers. The balance of 1996 was positive, as this period corresponded to the implantation of the program and to the definition of its guiding principles, both in terms of investigation and clinical assistance.
} 
in this order: a first consultation of neurological evaluation, followed by a genetic counseling session and psychological evaluation. Approximately three weeks later there is a second genetic counseling session that includes a social evaluation. At this appointment the consultant can then decide whether to pursue presymptomatic testing using direct gene analysis. Results are provided at a third counseling session if the consultant states he/she would like to know the results of the testing. Both short- (three weeks post disclosure) and long-term psychological follow-up (at six and twelve months) are offered to all participants, who voluntarily choose to participate. This protocol is flexible and tailored to the needs of the consultant and can be used as a model for other genetic diseases (e.g., familial amyloid polyneuropathy of type I, FAP-I). Continued psychosocial follow-up evaluation is offered at six months and annual neurological evaluations are recommended every year for those who test gene positive.

The goal of this program is to provide education and counseling to at-risk individuals so as to help them decide whether testing is the best decision for them at this time point and also to ensure that they are prepared for the outcome of their decision. Specifically, the psychologist's action includes the comprehension and evaluation of motivation, needs and psychological reactions of consultants and their relatives, as well as the promotion of their emotional expression, so that they can make informed and thoughtful decisions about presymptomatic testing and many life related areas.

The National Program of Presymptomatic Testing and Genetic Counseling in MJD also includes a number of psychological research goals, namely to identify the possible psychosocial predictors of adherence (acceptance/rejection) to testing, to improve psychological evaluation protocols and to develop efficient psychological intervention strategies, aimed at preventing emotional disturbances caused by the genetic result. Therefore, it is important to develop instruments for psychological evaluation of individuals interested in presymptomatic testing in order to "foresee situations of psychosocial risk and the underlying difficulties in subjects who are looking for a service of medical genetics" (Paúl, 1997, p. 248). The purpose of this paper is to present the development of a measure, the Perceived Advantages and Disadvantages of Presymptomatic Testing Inventory (PADI), intended to assess the subjective dimensions (expectations) of the decision-making

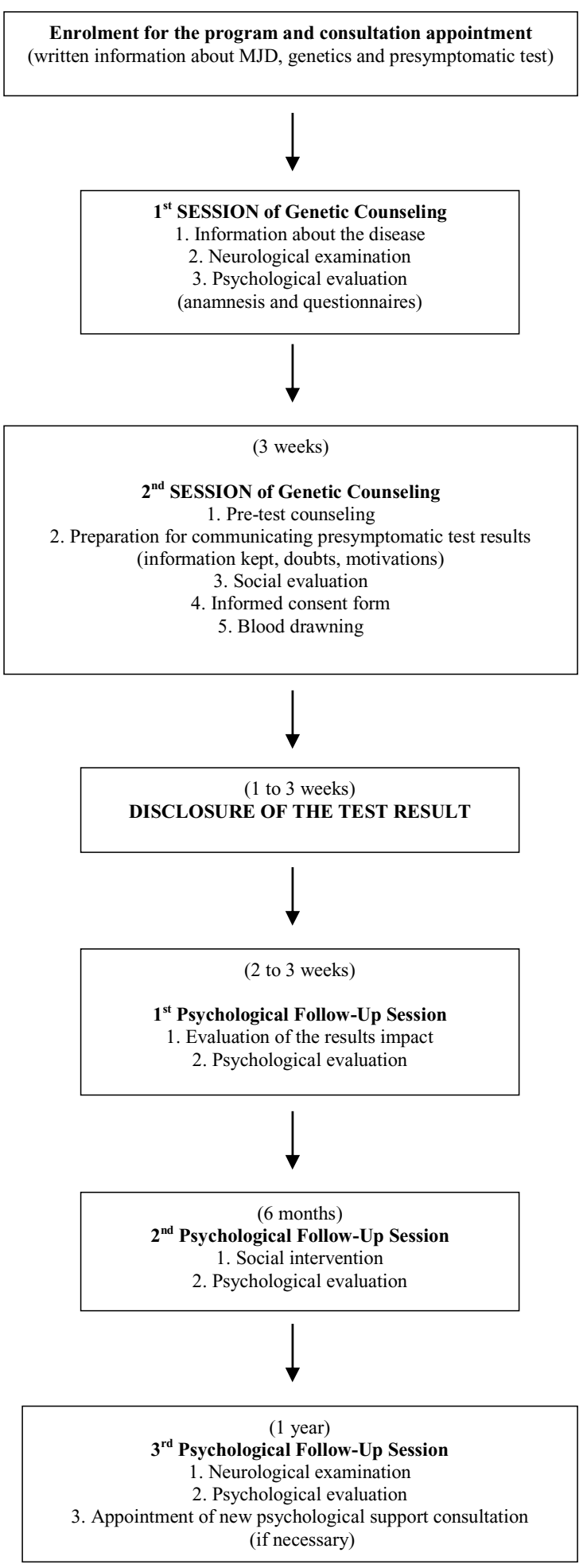

Fig. 1. Consultation protocol of the National Program of Presymptomatic Testing and Genetic Counseling in MachadoJoseph disease (adapted from Sequeiros, 1996b, p. 133). 
process, about the MJD presymptomatic testing, and the evaluative dimension of perceived benefits and harms that people at genetic risk relate to presymptomatic diagnosis.

\section{Theoretical Basis of the Perceived Advantages and Disadvantages of Presymptomatic Testing Inventory}

In the development of the PADI we first considered how presymptomatic testing is experienced. Presymptomatic test for autosomic dominant diseases, like MJD or HD, may be experienced as a meaningful life event (Hayden et al., 1988), due to the set of decisional dilemmas, which individuals at genetic risk must face (Fleming and Lopes, 2000; Motulsky, 1994). It is almost certain that an early detection of heterozygous condition can cause, in people who are uncertain about the possible inheritance of a molecular mutation, complex decision-making problems (Evers-Kiebooms et al., 1989; Salkovskis et al., 1999; Taylor, 2002) that are influenced by multiple psychological and social aspects (Bird, 1999; Paúl, 1997). Therefore, the study of decision-making process, in genetic contexts, and the factors that contribute to individual decision taking, seems to be an important contribution to modern psychological research (Lerman et al., 2002) and support. These types of studies are important in the area of genetics, as the decision to screen is the pivotal decision point in this approach.

The process of decision-making, in situations that involve the risk of developing a genetic disease, may be perceived as a cognitive activity, which is mediated by emotional answers (e.g., concern, fear, anxiety) and this way not entirely rational (Timmermans and Henneman, 2002). In the development of this measure we focused on both the cognitive component, which characterizes most decisions, and the role-played by emotions and their importance for decision-making in situations of uncertainty. To help understand the cognitive and emotional components we utilized the Decisional Conflict Theory, the Health Belief Model, and the Transtheoretical Model of Behavioral Change.

Decisional Conflict Theory by Janis and Mann (1977) proposes that stress interferes with the ability to consider the salient features of a situation and to deliberate carefully about the pros and cons of alternative options.

The Health Belief Model (HBM) (Rosenstock, 1974) is a decisional model of cognitive orientation. This model was developed to integrate differ- ent health beliefs and to predict health behaviors or intentions. The model rest on the premises that individuals are rational information processors (for example, the HBM assumes that the individual weighs up the pros and cons of a behavior, assesses the seriousness of a potentially dangerous illness and then decides how to act), and that decisions are based on beliefs, so the discernment of these beliefs can contribute to the prediction of future health behavior (Ogden, 2004). The HBM was used, in our study, as the foundation and theoretical framework for the constructs and items comprising the measure we developed. According to the HBM, the actions towards health (or the motivation to look for medical care) will depend on the subjective meaning attributed to the disease, on the perceived efficiency and on the perceived costs of medical procedure. The higher the perceived susceptibility and the perceived severity of the disease, the higher the health threat and thus the individual will engage, more likely, in health behaviors. Further, the likelihood of engaging in this behavior will depend on the extent to which the individual believes that the action yields benefits (in reducing susceptibility and/or the severity of the condition), which outweigh the barriers. This model may be described as an integrating approach to constructs of cognitive kind (perceived susceptibility and perceived seriousness of the disease) and of motivational kind (balance of costs and benefits), related to the enhancement of health promoting actions.

The Transtheoretical Model (TTM) of behavioral change (Prochaska and DiClemente, 1983), which posits that different processes of change are useful at different stages of change (precontemplation, contemplation, preparation, action and maintenance), was also considered in the development of the measure. The TTM incorporates intermediate outcome variables, which predict progress across the stages of change (Norman et al., 2004; Velicer et al., 1995): the pros and cons of change from decisional balance theory (Janis and Mann, 1977).

It has been suggested that decision-making involves the implicit weighing up of those advantages and disadvantages of possible options, considered relevant at the time the decision is made (Salkovskis et al., 1999). Harrison et al. (1992), Hillner (1996), and others, have focused on the perception of costs/benefits in the enhancement of behavior related to health.

The evaluative and motivational dimension can be considered relevant for taking an option towards MJD presymptomatic diagnosis (Paúl et al., 2000) 
and prenatal diagnosis (Andrade et al., 1998), in the overall context of genetic counseling and psychological support.

\section{Reasons for the Construction of the Inventory}

Bearing in mind the decision-making theory and research (Janis and Mann, 1977; Rosenstock, 1974; Salkovskis et al., 1999) and that there are not empirical studies about the analysis of the binomial equation pros/cons or any instrument to evaluate that attitudinal component (cognitive-evaluativemotivational), as far as MJD presymptomatic testing is concerned, we decided to construct and study the psychometric qualities of a self-rating instrument on the subjective expectations of people at genetic risk for MJD facing presymptomatic testing.

The measure of the perceived advantages and disadvantages, constructs derived from the HBM, was developed to assess the decisional consideration process related to MJD presymptomatic testing. Decisional consideration can be theoretically defined as the "extent to which a person values or prioritizes the positive and negative aspects of a particular behavior" (Vernon et al., 1999, p. 354). In other words, we assess people's cognitive appraisal of the positive (pros) and negative (cons) aspects of doing MJD genetic test. By focusing on this specific disorder and on the subject's perceptions about genetic testing, we think we can improve our understanding about decision-making for genetic screening behaviors.

\section{METHODS}

\section{Sample}

The study subjects belong to genetically identified families with MJD and whose relatives attended Portuguese medical centers in Porto, Coimbra, Santarém as well as Angra do Heró́smo in Azores. Study subjects were identified through physician referral and personally contacted, by the first author of this study (LR), who has explained them the purposes of the investigation and invited them to participate. All individuals agreed to take part in the study. Our study was approved by the institutional ethics committees.

The total sample included 44 individuals (23 women and 21 men) at genetic risk for MJD, non- symptomatic, aged between 18 and 61 years (average age: $34.57 \pm 11.19$ years), $70.5 \%$ of them were married, $50.4 \%$ had, at least, one child, $59.1 \%$ had 6 to 9 schooling years of education, $25 \%$ had less than 5 schooling years and $15.9 \%$ had completed high school or had a University degree.

\section{Measurement Development}

\section{Semistructured Interviews}

In the development and study of the measure, we first completed semistructured interviews. The interviews were developed by LR and JAZC, in order to obtain socio-demographic information and to monitor self-response questionnaires. The subjects were invited to read an introductory letter explaining the nature and purpose of the study and to fill in a consent form for participation. After obtaining written informed consent, we completed a registration sheet containing items assessing socio-demographic data and several open-ended questions addressing family history of the disease, knowledge and experience about the disease, genetic risk and presymptomatic testing (these information will be presented elsewhere). Next, participants were asked to fill in the questionnaires (described below); the PADI was the last one to be presented.

The interviews were conducted by LR, either in the medical center or in the subjects home. The mean duration of the interviews was 45 to $60 \mathrm{~min}$. All the subjects interviewed stated they were interested in doing the presymptomatic testing for MJD. As they were interviewed in a previous phase to their possible participation in the presymptomatic testing program, these individuals will be acknowledged, in the present study, as candidates to the program.

\section{Socio-Demographic Variables}

The 4 defined age groups were: 1 [18-23 Years]; 2 [24-29 Years]; 3 [30-39 Years]; $4 \geq 40$ years. Marital status was categorized into two groups: 1 -Single/Separated/Divorced/Widower and 2-Married/Common Law. Number of children was divided into: 0 -Without children and 1-One or more children. The considered educational levels were: $1-\leq 5$ years; $2-6$ to 9 years (basic schools); 3-10 to 12 years (secondary schools); 4-over 12 
Table I. Perceived Advantages and Disadvantages of the MJD Presymptomatic Testing

\begin{tabular}{|c|c|}
\hline Advantages & Disadvantages \\
\hline $\begin{array}{l}\text { - Reducing the individual } \\
\text { uncertainty }\end{array}$ & $\begin{array}{l}\text { - Perceived incapability of } \\
\text { personal adaptation to the } \\
\text { test result }\end{array}$ \\
\hline $\begin{array}{l}\text { - Reducing the individual } \\
\text { anxiety (reassurance) }\end{array}$ & $\begin{array}{l}\text { - Perceived negative } \\
\text { consequences coming up } \\
\text { from knowing a carrier result: }\end{array}$ \\
\hline $\begin{array}{l}\text { - Getting certainty about } \\
\text { whether he/she will develop } \\
\text { the disease }\end{array}$ & $\begin{array}{l}\text { - Increased anxiety and fear } \\
\text { about the future }\end{array}$ \\
\hline $\begin{array}{l}\text { - Getting certainty about the } \\
\text { chances of passing the } \\
\text { disease on to the offspring }\end{array}$ & $\begin{array}{l}\text { - Anxiety among family } \\
\text { members }\end{array}$ \\
\hline - Planning the future & $\begin{array}{l}\text { - Negative effects on } \\
\text { relationships with others in } \\
\text { the family }\end{array}$ \\
\hline $\begin{array}{l}\text { - Informing children about } \\
\text { their genetic risk }\end{array}$ & $\begin{array}{l}\text { - Hipervigilance and worry } \\
\text { about minor symptoms }\end{array}$ \\
\hline \multirow[t]{2}{*}{$\begin{array}{l}\text { - Beginning possible medical } \\
\text { action }\end{array}$} & $\begin{array}{l}\text { - Concerns about insurability } \\
\text { and discrimination (life, } \\
\text { health, disability) }\end{array}$ \\
\hline & - No cure for the disease \\
\hline
\end{tabular}

years (post-secondary education/degree, BSc, college graduation, Master Degree, $\mathrm{PhD}$ ).

\section{Item Development for the Perceived Advantages and} Disadvantages of Presymptomatic Testing Inventory

The relevant variable for this study is related to the cognitive-motivational dimension of attitudes to MJD presymptomatic testing, more precisely to the costs and benefits perceived by the individuals at genetic risk. The Perceived Advantages and Disadvantages of Presymptomatic Testing Inventory (PADI) items identification was determined by:

1. The spontaneous pointing out of reasons for doing presymptomatic testing by the first participants in the National Program of Pre-Symptomatic Testing and Genetic Counseling in MJD, during the pre-screening interview of psychological evaluation included in the program protocol. Table I summarize the reasons for (pros) and against (cons) pre-symptomatic testing, spontaneously enhanced by at-risk individuals for MJD;

2. The experience obtained with the administration of the Presymptomatic Testing Acceptance Scale-PTAS (Paúl, 1997). We have concluded that there was a need to use a specific instrument to evaluate the dimension of costs and benefits, to focus on completely forgotten aspects in PTAS (items 2, $4,6,7,8,9,12,13,14,15$ and 16 of PADI; cf. Appendix), and to write items with a simpler and less dubious interpretation;

3. Comprehensive literature review concerning the motivation for doing the presymptomatic diagnosis of HD (e.g., Bloch et al., 1989; Craufurd et al., 1989; Decruyenaere et al., 1993, 1997; Evers-Kiebooms, 1989; EversKiebooms et al., 1989; Jacopini et al., 1992; Meissen et al., 1988; Tyler and Harper, 1983; van der Steenstraten et al., 1994);

4. The awareness of the experience with the construction and administration of a scale evaluating the expectations related to the decision-making about pre-natal diagnosisthe Perceived Costs and Benefits of PreNatal Diagnosis Scale (Andrade et al., 1998).

Considering these pieces of information, we have made a list of benefits (arguments for the presymptomatic diagnosis) and of costs (arguments against) of doing MJD presymptomatic testing. The statements were then reviewed by health professionals and further refined in a small sample of individuals at-risk for MJD. During the PADI administration, people were invited to reflect, to make comments on the formulation and ordering of the items, to point out their difficulties in understanding and to suggest other aspects not observed in this inventory. These comments were taken into account in the analysis and selection of items to form the latter version of the PADI. Given the absence of any difficulty in understanding or answering the questions, all items were retained at this point.

This inventory is composed, in its original version, by a pool of 16 attitudinal items (see Appendix), addressing reasons as to why a subject would decide to pursue or decline MJD presymptomatic testing. The scoring of the answers obey to a dichotomic ${ }^{7}$ structure (YES/NO), so that whenever the subject

\footnotetext{
${ }^{7}$ This classifying system is simple, objective and more accessible (Nunnally, 1978) for the majority of individuals, who are thus not faced with the difficulty of having to choose between too close answering (e.g., I completely agree and agree; I completely disagree and disagree). On the other hand, in Likert scales, the answers do not always express the true attitude of individuals, since many of them are led to answer the items in systematically extreme or neutral ways (Simões, 1987).
} 
agrees with the reason a point is given and whenever he/she disagrees with the pointed out reason he/she gets zero points.

The items are divided into 8 reasons for (advantages/pros) and 8 reasons against (disadvantages/cons) the presymptomatic testing. Similar to Vernon et al. (1999) and Ho et al. (2003), we examined the pros and cons separately and produced a general score (pros minus cons) representing the decisional balance or trade-off between the perceived advantages and disadvantages of doing presymptomatic testing. Higher scores indicate that the subject tends to emphasize the advantages (gains) of screening and lower scores imply that harms (negative consequences) are considered more important than benefits in the decisional consideration process.

The option for the bipolar conception of PADI (this is for the separation of reasons into pros and cons) is based on the assumption that people are guided, in more or less rational terms, in the decisions they make, by balancing benefits and costs of each of the existing alternatives (Andrade et al., 1998). The list of reasons we generated include personal, familial and social areas. We believe these aspects are considered throughout the process of the presymptomatic testing from decision-making, testing, waiting for the result, and finally learning the test outcome.

\section{Reliability and Validity of the PADI}

The methodological approach to the construction of the PADI involved four main steps labeled: (1st) reliability study; (2nd) factorial validity study; (3rd) sensitiveness to differences of gender, age and educational level study; (4th) construct validity studies.

This last section included the study of social desirability association with PADI scores, for what we have used the Social Desirability Scale (SDS; Crowne and Marlowe, 1960), and the study of the PADI convergent validity, by means of correlation studies with the Attitudes towards Doctors and Medicine Questionnaire (ADMQ; Marteau, 1990), and with the Perceived Emotional Burden Related to the Genetic Disease Scale (PEBGDS; ZagaloCardoso, 1995). These studies were complemented by a correlation study between PADI and the Predictive Testing Acceptance Scale (PTAS; Paúl, 1996).

\section{Social Desirability Scale}

The Social Desirability Scale (SDS; Crowne and Marlowe, 1960), adapted by Simões and Lima (1992) and used by Andrade (1997), in the context of genetic counseling, with individuals of the Portuguese population, is composed of 24 items, which correspond to culturally approved behaviors. It is a scale with a dichotomic format of true/false answers; score 1 is attributed when the answer reflects social desirability (i.e., the tendency to give answers from which a greater social approval may result) and score 0 whenever this indicator is omitted. The scale internal consistency has proved to be satisfactory, according to the Kuder-Richardson (K-R) coefficient (.73).

Our aim was to check the influence of social desirability on PADI results and, consequently, on their construct validity, supposing that the latter will be the greater, the less guided by a wish of social approval the answers are.

\section{Attitudes Towards Doctors and Medicine Questionnaire}

Attitudes towards Doctors and Medicine Questionnaire (ADMQ; Marteau, 1990), in its Portuguese version (Andrade, 1997), is characterized by a system of multiple scoring, of the Likert type, and is composed of 17 items, selected in relation to their discriminatory power and metrical characteristics, while having a reasonable internal consistency, as revealed by the obtained alpha coefficient (.73). This questionnaire was develop to evaluate the attitudes facing doctors' efficiency in the promotion of health and it is composed of 2 factors: Factor 1-Negative Attitudes towards Doctors and Medicine and Factor 2-Positive Attitudes towards Doctors and Medicine.

In the same way as Andrade (1997), we have chosen to use, in our research, only the ADMQ total, due to the fact that the two sub-scales do not present a structure similar to the original version of the scale and are a little less consistent than the global scale.

We hope to find support for the PADI convergent validity, owing to the affinity between the attitudinal objects evaluated by this inventory and by ADMQ: the one of the first scale specifically mentions a new health service that allows MJD presymptomatic diagnosis; the one of the second scale is more 
generic and is directed to a macroscopic perspective of the health care and its agents.

\section{Perceived Emotional Burden Related to the Genetic Disease Scale}

The Perceived Emotional Burden Related to the Genetic Disease Scale (PEBGDS; Zagalo-Cardoso, 1995) is composed of 24 items. The answers are scored under the Likert type, with a scoring from 1 to 5, and the total score can range from 24 to 120 , the higher scores indicating greater perceived emotional burden. The scale has got satisfactory internal consistency $(\alpha=.78)$ and possesses satisfactory construct validity, because it can differentiate known groups (e.g., diseases with diverse clinical severity).

PADI is specifically directed to the evaluation of the arguments for and arguments against presymptomatic testing for a late onset incurable disease. The second factor of the inventory (perceived barriers) reflects, namely, the personal and familial burden imposed by that plan of action. Based on the structural affinity between PADI and PEBGDS, and on empirical data (Zagalo-Cardoso, 1995), we hypothesized that there will be a significant association between the perception of the burden related to the genetic disease and each of the PADI dimensions (perceived advantages and perceived disadvantages of MJD presymptomatic testing).

Consequently, it is perfectly acceptable that PEBGDS may be used to evaluate certain aspects of PADI's convergent validity.

\section{Predictive Testing Acceptance Scale}

The Predictive Testing Acceptance Scale (PTAS; Paúl, 1996) is a one-dimensional (pointing out the predictive testing acceptance) self-evaluation scale, of the Likert type. It is composed of 24 items and has a decreasing classifying system, from 4 to 1 , according to the signaled option: completely agree, agree, disagree and completely disagree. The factorial analysis in main components, followed by a Varimax type rotation, has revealed 3 factors: Factor $1\left(\mathrm{~F}_{1}\right)$-Fears towards the Presymptomatic Test; Factor $2\left(\mathrm{~F}_{2}\right)$-Planning the Future; Factor $3\left(\mathrm{~F}_{3}\right)$-Reducing Uncertainty. As a whole, the three defined dimensions explain $37 \%$ of the total variance; in what concerns the specific variances,
Factor 1 explain $15.7 \%$, Factor $2-12 \%$ and Factor 3-9.3\%. The internal consistency of the three subscales, determined by Cronbach alpha coefficients, was .38 to the third sub-scale, a value which contrasts with the homogeneity of the items belonging to the first two sub-scales: $\alpha_{1}=.60$ e $\alpha_{2}=.53$. In this study, we will use a version of PTAS reviewed and updated, in terms of psychometric qualities (Rolim and Zagalo-Cardoso, in press), composed of 18 items (without items 1, 7, 13, 17, 22 and 23 of the original version), whose Cronbach alpha coefficients have proved to be more satisfying than the previous ones: scale $(\alpha=.66)$ and sub-scales, respectively, $\alpha_{1}=.85$, $\alpha_{2}=.76$ and $\alpha_{3}=.60$.

\section{Statistical Analysis}

Means, standard deviations, and frequencies were generated to describe the data and ensure suitability for parametric statistical analysis. $\chi^{2}$ tests were performed to determine whether there were significant differences between frequencies of answers to PADI items. Pearson product-moment correlations, K-R coefficients and even-odd correlations were computed to evaluate the internal consistency of the PADI. Factorial analyses were conducted to examine the underlying factor structure of PADI. Eigenvalues $>1.5$ and factor loadings $>.30$ were sought. Betweenparticipants $t$ tests and bivariate correlations were computed to test sensitiveness of PADI to differences of gender, age and educational level, and to determine the effects of social desirability. A $p$ value of .05 was used for all statistical tests, as the threshold for statistical significance.

Next we'll describe the results obtained in each of the above-mentioned stages.

\section{RESULTS}

\section{Descriptive Statistics of the PADI Items}

Table II shows some descriptive data about means, standard deviations and frequencies (percentages) of item scores. As it is possible to observe, the means have varied between .386 (item 3 ) and .932 (item 10), and the standard deviations have varied between a minimum of .255 (item 10) and a maximum of .506 (item 1). Item 1 presents a balanced distribution of the answers' frequencies 
Table II. Means, Standard Deviations and Frequencies (Percentages) of Item Scores $(N=44)$

\begin{tabular}{|c|c|c|c|c|}
\hline Items & Means & $\begin{array}{c}\text { Standard } \\
\text { deviations }\end{array}$ & Yes & No \\
\hline 1 & .500 & .506 & $\mathbf{5 0 . 0}$ & $\mathbf{5 0 . 0}$ \\
\hline 2 & .520 & .505 & 52.3 & 47.7 \\
\hline 3 & .864 & .347 & 86.4 & 13.6 \\
\hline 4 & .386 & .493 & 38.6 & 61.4 \\
\hline 5 & .705 & .462 & 70.5 & 29.5 \\
\hline 6 & .450 & .504 & 45.5 & $\mathbf{5 4 . 5}$ \\
\hline 7 & .520 & .505 & 52.3 & 47.7 \\
\hline 8 & .450 & .504 & 45.5 & 54.5 \\
\hline 9 & .640 & .487 & 63.6 & 36.4 \\
\hline 10 & .932 & .255 & 93.2 & 6.8 \\
\hline 11 & .610 & .493 & 61.4 & 38.6 \\
\hline 12 & .750 & .438 & 75.0 & 25.0 \\
\hline 13 & .550 & .504 & 54.5 & 45.5 \\
\hline 14 & .820 & .390 & 81.8 & 18.2 \\
\hline 15 & .550 & .504 & 54.5 & 45.5 \\
\hline \multirow[t]{4}{*}{16} & .660 & .479 & 65.9 & 34.1 \\
\hline & \multicolumn{2}{|c|}{ PADI statistics $(N=44)$} & \multicolumn{2}{|c|}{ Mean \% answers } \\
\hline & & & Yes & No \\
\hline & $M=9.910$ & $S D=2.361$ & 61.9 & 38.0 \\
\hline
\end{tabular}

Note. $M$ : mean; $S D$ : standard deviation.

(50-50\%), between both options, which suggests that the procreative decisions, that may be made, in the sequence of MJD diagnosis, have constituted, for half of the people interviewed, an argument for test taking. We found statistically significant differences in the distribution of the answers' frequencies to item 3 $\left[\chi^{2}(1)=23.273, p<.001\right]$, once a substantial percentage of people $(86.4 \% ; 38$ out of 44$)$ have considered the possibility of informing their children about their own genetic risk as one of the reasons that may determine testing uptake, as opposed to $13.6 \%$ of people $(n=6)$ that denied the relevance of that argument. In item 5, the majority of respondents $(70.5 \%$; $n=31$ ) concluded that presymptomatic testing would permit a better mid and long-term planning of living conditions $\left[\chi^{2}(1)=7.364, p<.010\right]$. For item 10, we found that the majority of people $(93.2 \% ; n=41)$ agreed that genetic testing will allow them to have access to objective genetic information and would clarify their doubts about their state of risk for the disease $\left[\chi^{2}(1)=32.818, p<.001\right]$. Seventy-five percent $(n=33)$ agreed that opting for presymptomatic diagnosis has got some benefits, in terms of medical assistance (item 12). In contrast, $25 \%(n=11)$ of the respondents did not agree that there was any medical benefit in knowing gene status $\left[\chi^{2}(1)=11, p<.010\right]$. The better organization of the daily routine and the resulting improvement of life quality and well-being (item 14) seemed to be a relevant argument for presymptomatic testing, because it attained a consensus among a high proportion of people $(81.8 \%$; $n=36)$, in contrast with only $18.2 \%(n=8)$ of people who considered that test taking wouldn't cause any changes in their personal life style $\left[\chi^{2}(1)=17.818\right.$, $p<.001]$. Thirty four percent $(n=15)$ did not feel that genetic testing uptake might lead to the detachment of close people (item 16$)$ and $65.9 \%(n=29)$ have accepted, as possible, this consequence in interpersonal relationships $\left[\chi^{2}(1)=4.455, p<.050\right]$.

\section{1st Stage: Reliability Study}

The reliability study and thus the homogeneity of the items were supported by the analysis of some indicators: (1) the matrix of intercorrelations between the items; (2) the Pearson correlation coefficient item-total; (3) the K-R coefficient for the whole inventory and each of its sub-scales without the item; (4) the even-odd correlations.

These criteria aimed to evaluate the contribution of each item for the internal consistency of the PADI, but, at this stage, they were not applied to exclude the less homogeneous items in relation to the content of the inventory.

The matrix of intercorrelations showed that the items seem to build a consistent set in which linking dimensions among some items are drawn.

Table III summarizes the metrical characteristics of the PADI items, relating to the abovementioned criteria 2 and 3 . As we can see, the items $1,3,5,6,7,8,9,10,12,13,14,15$ and 16 are correlated in a statistic significant way to the total of PADI. All of these correlations were moderate (less than .70) and over .20, a score pointed out by some authors (Nunnaly, 1978; Streiner and Norman, 1989) as the limit from which the items are considered consistent with the construct the test aims to evaluate. The correlations between items 2, 4, 11 and the total are very low and not statistically significant; items 4 and 11 are correlated in a negative and not significant way to the total of the inventory.

The score of the K-R coefficient for the PADI global score was .447 , and .675 and .379 , respectively, for the perceived advantages (pros) and disadvantages (cons). Bearing in mind that the majority of investigators (Bellack and Hersen, 1976; Nunnaly, 1978; Stevens, 1992) define values between .70 and .80 as acceptable indicators of the homogeneity of the 
Table III. Metrical Characteristics of the PADI Items

\begin{tabular}{|c|c|c|c|c|}
\hline \multirow[b]{3}{*}{ Items } & \multirow[b]{3}{*}{$r$ total-item } & \multicolumn{3}{|c|}{$(N=44)$} \\
\hline & & \multirow[b]{2}{*}{$p$} & \multicolumn{2}{|c|}{ K-R (without item) } \\
\hline & & & Pros & Cons \\
\hline 1 & $.499^{* *}$ & .002 & .692 & \\
\hline 2 & .040 & NS & & .478 \\
\hline 3 & $.498^{* *}$ & .001 & .624 & \\
\hline 4 & -.001 & NS & & .459 \\
\hline 5 & $.505^{* * *}$ & .000 & .605 & \\
\hline 6 & $-.565^{* * *}$ & .000 & & .272 \\
\hline 7 & $-.409^{* *}$ & .006 & & .264 \\
\hline 8 & $-.448^{* *}$ & .002 & & .272 \\
\hline 9 & $.440^{* *}$ & .003 & .627 & \\
\hline 10 & $.421^{* *}$ & .004 & .651 & \\
\hline 11 & -.102 & NS & & .466 \\
\hline 12 & $.317^{*}$ & .036 & .674 & \\
\hline 13 & $.364^{*}$ & .015 & 672 & \\
\hline 14 & $.576^{* * *}$ & .000 & .602 & \\
\hline 15 & $-.537^{* * *}$ & .000 & & .283 \\
\hline \multirow[t]{2}{*}{16} & $-.511^{* * *}$ & .000 & & .176 \\
\hline & & & $K-\mathrm{R}=.675$ & $\mathrm{~K}-\mathrm{R}=.379$ \\
\hline
\end{tabular}

Note. $r$ : Pearson correlation (bilateral); NS: non-significant correlation.

${ }^{*} p<.050$.

$* * p<.010$.

${ }^{* * *} p<.001$.

items that compose a scale, we can conclude that only the K-R coefficient of the first dimension of PADI comes closer to the inferior limit of that range. This way, and due to our option of dealing separately with each sub-scale, we have decided to investigate the contribution of each item to the internal consistency of the respective dimension.

Although item 1 does not add to the internal consistency of the perceived advantages sub-scale, as in its absence K-R coefficient increases from .675 to .692, we have decided not to exclude it from the inventory, owing to its significant correlation with the total score $(r=.499 ; p<.010)$.

The K-R coefficients for each question, with its own exclusion, show that when items 2, 4 and 11 are not included the values increase above the global score of the perceived disadvantages dimension (K$\mathrm{R}=.379$ ), which means that these items do not improve its internal consistency. To confirm this fact, as we can remember, these same items $(2,4$, and 11$)$ do not present significant correlations with the total. These are arguments strong enough to pursue the validity studies without them.

The score of the K-R coefficient for the inventory, without items 2,4 and 11, was higher (.540) than the one reported for the original version of 16 items
$(\mathrm{K}-\mathrm{R}=.447)$. Also, the reliability of the cons dimension had a considerable improvement, without those three items, from .379 to .816 , which is a confirming element of the homogeneity of the items that compose it, if we consider that this score is higher than the superior limit of the interval between .70 and .80 , corresponding, as we said before, to the more acceptable coefficients. The even-odd correlation, for the reduced version (13 items version) of the PADI, was $.439(p<.010)$.

\section{2nd Stage: Factorial Validity Study}

Due to the PADI internal logical construction and the reasons stated in the previous stage, we decided to do a confirmatory factorial analysis ${ }^{8}$ with the extraction of two factors (see Table IV), by means of a confirmatory factorial analysis, with the method of extraction in Principal Components followed by an orthogonal rotation of the axis (Varimax type). The factorial solution that was found was characterized by two dimensions, clearly reflecting people's cognitive appraisal of the positive (advantages/pros) aspects (items 1, 3, 5, 9, 10, 12,13, and 14) and negative (disadvantages/cons) consequences (items 6, 7, 8, 15 and 16) of doing the presymptomatic diagnosis.

In their whole, the factors accounted for $43.87 \%$ of the total variance. The first dimension was characterized by 7 items and contributed with $21.33 \%$ for the total variance; the second dimension included 5 items and accounted for the highest percentage $(22.55 \%)$ of the explained total variance. The correlation between the two factorial scores was not significant $(r=-.251)$, which corroborate the relative independence of the underlying dimensions.

In Table IV, are the eigenvalues, which correspond to the variance of the principal components, the communalities for each item (i.e., the proportion of each item variance, represented by this

\footnotetext{
${ }^{8}$ Whereas some statisticians advise against the use of factor analysis with dichotomous variables (e.g., Gorsuch, 1983; Streiner, 1994), several other authors (Cattell, 1978; Kim and Mueller, 1978; Rummel, 1970) and extensive data show that it can be useful. Drawing a parallel with dummy variable regression, Cattell (1978) stated that a loading for 0-1 scaled variables can be interpreted in two ways: as the probability of its presence (if the loading is positive) or absence (if negative), given that the factor exists. Also, Kim and Mueller (1978) allow the use of factorial analysis with dichotomous data, if the underlying metric correlations between the variables are moderate (.70) or lower. This last condition was fulfilled (as we referred in the First Stage: Reliability Study), so it was possible to perform factor analysis.
} 
Table IV. PADI Factorial Solution, without Items 2, 4, and 11 $(N=44)$

\begin{tabular}{lcc} 
& $(N=44)$ & \\
\hline Items & Loading & $\mathrm{H}_{2}$ \\
\hline Factor 1: Perceived advantages (pros) & \\
1 & .310 & .150 \\
3 & .678 & .464 \\
5 & .733 & .549 \\
9 & .575 & .331 \\
10 & .560 & .355 \\
12 & .369 & .137 \\
13 & .490 & .241 \\
14 & .769 & .617
\end{tabular}

Eigenvalue: 2.12 , explained variance: $21.33 \%$

Factor 2: Perceived disadvantages (Cons)

$6 \quad .720 \quad .570$

$\begin{array}{lll}7 & .805 & .579\end{array}$

$\begin{array}{lll}8 & .761 & .580\end{array}$

$\begin{array}{lll}15 & .691 & .534\end{array}$

$\begin{array}{lll}16 & .779 & .607\end{array}$

Eigenvalue: 3.58 , explained variance: $22.55 \%$

Note. $h_{2}$ : communalities; K.M.O.: Kaiser-Meyer-Olkin; $d f$ : degrees of freedom. Factorial analysis statistics: Total variance explained by the factors: $43.87 \%$. K.M.O. $=.616$. Bartlett's Test of Sphericity $=178.326(d f=78 ; p<.001)$.

factorial structure and explained by the retained principal components), and the percentage of variance explained by each factor and by all of them.

Other factorial analysis statistics guarantee the adequacy of the factorial model to the intercorrelations matrix: the Kaiser-Meyer-Olkin (KMO) measure, which value (.616) is close to the unity, and the Bartlett's Test of Sphericity, which refuse the hypothesis of the correlations matrix being the identity matrix with a determinant equal to one.

The PADI reduced version (13 items) was used in the following studies.

\section{3rd Stage: Sensitiveness to Differences of Gender, Age and Educational Level Study}

In the studied clinical sample $(N=44)$, the women's sub-group $(M=3.04 ; S D=2.95)$ and the men's sub-group $(M=3.19 ; S D=3.14)$ are equivalent in what concerns the total score of the PADI current version $[t(42)=.160, p=.873]$. The findings are similar related to the perceived advantages $[t(42)=.896, p=.375]$ and the perceived disadvantages $[t(42)=1.152, p=.256]$ of the MJD presymptomatic testing.
Pearson correlations between age and each of the PADI scores (pros, cons and total) were not statistically significant. Also, we did not detect any significant correlations between educational levels (expressed in years) and PADI scores. The PADI answers were not presumably influenced by differences of gender, age or educational level.

\section{4th Stage: Construct Validity Studies}

\section{Association Between Social Desirability and PADI Scores}

There is no statistically significance correlation between the total results of PADI and SDS $(r=-.117, p=.450)$, and between the total SDS and each one of the PADI dimensions, pros $(r=-.058$, $p=.707)$ and cons $(r=.127, p=.413)$. So, we can conclude that social approval may not have influenced the answers to the PADI. This fact adds an additional element to the PADI construct validity, once the PADI and SDS aim to evaluate different constructs (attitudinal objects).

\section{Convergent Validity}

We found that the Pearson correlation between ADMQ and the total score of the PADI was not statistically significant. However, we obtained a positive and significant correlation between ADMQ and the perceived advantages sub-scale of the PADI $(r=.377, p<.050)$; also, the correlation between ADMQ total score and the negative cognitive appraisal of undertaking presymptomatic testing had statistical significance $(r=-.352, p<.050)$. We can infer, from this result that, as theoretically expected, the greater the confidence on doctors and medicine in general, the higher are the scores of the pros dimension and the lower are the values of the cons sub-scale. Consequently, stronger importance will be given to the advantages of the genetic diagnosis, than to its disadvantages. In sum, the PADI convergent validity (for both of its dimensions), in relation to ADMQ, was satisfactory confirmed.

In the same way, a significant association between the PEBGDS total scoring and the PADI cons dimension $(r=-.316 ; p<.050)$ was obtained, which reveals, as expected, that the high perceived burden, caused by such a serious disease as MJD, 
corresponds, in the subjects at genetic risk, to a least unfavorable evaluation of the presymptomatic diagnosis.

There was no statistically significant relationship between PEBGDS and the PADI perceived advantages dimension $(r=.104 ; p=.500)$. For this reason, the PADI convergent validity, with reference to PEBGDS, was partially established, as it was confirmed only at the level of the perceived negative aspects of presymptomatic diagnosis.

We have also compared the total of the PTAS, in its reduced version (Rolim and Zagalo-Cardoso, in press) composed of 18 items, to the PADI (13 items version), and found that there is a positive and moderate correlation between them $(r=.393, p<.050)$. The total PTAS is also statistically associated to the PADI first factor $(r=.412 ; p<.010)$ and to the second inventory factor $(r=-.332 ; p<.050)$.

To summarize, there are important correlations between the total PTAS and the total PADI and each of its factor, though they have moderate values, which suggests that the instruments have some affinity but they do not measure the same construct.

\section{DISCUSSION}

In this study, we developed an instrument (the Perceived Advantages and Disadvantages of Presymptomatic Testing Inventory, PADI) for measuring perceived benefits and harms that people at genetic risk relate to presymptomatic diagnosis. The instrument seems to capture relevant issues concerning these two evaluative dimensions. The items contained in the instrument appear relevant to the subjects and were found to be associated, as expected, with previously validated measures.

The interest of the PADI construction results from the importance of the cognitive-motivational dimension of the attitudes of subjects at genetic risk, towards the presymptomatic diagnosis. This issue regards the evaluation and balancing of perceived advantages (arguments for) and disadvantages (arguments against) involved in the possible course of action (Bird, 1999; Codori and Brandt, 1994; Kessler, 1994).

The lack of empirical studies on the analysis of the binomial equation pros/cons and of instruments to evaluate the variable perceived advantages and disadvantages of the presymptomatic testing, as far as the MJD test is concerned, made us to construct the PADI.

In the consultant's perspective, the possibility of presymptomatic diagnosis might bring some advantages (Rolim, 2000): the most obvious derives from the possibility of reducing anxiety; another has to do with the possibility of making responsible choices and taking right decisions regarding procreation, academic, professional and financial areas. There might be, however, disadvantages strictly connected with the practice of genetic testing, such as an increase in anxiety and psychological burden owing to an unfavorable result (Tibben, 2002). It is essential that individuals understand these advantages and disadvantages, prior to predictive health screening, in order to make an informed decision about testing.

Reliability analysis showed that items 2, 4 and 11 not only do not contribute to the PADI internal consistency, but also reduce it. If we look to the content of items 2, 4 and 11, we can understand why they are inconsistent with the rest of the inventory. A cure for the disease (item 2) is indeed irrelevant for the decision to take the presymptomatic test of an incurable disease, like MJD. Most people (61.4\%; 27 out of 44) have answered item 11 ("Taking the presymptomatic test can cause too much suffering, if I know that I'll have the disease") negatively, which indicates that, for them, the option for presymptomatic diagnosis is not a disruptive emotional factor. In fact, a large amount of respondents (93.2\%) considered the test as a method with psychoemotional advantages, while permitting the reduction of uncertainty (item 10: "Taking the presymptomatic test help to end doubts about the state of risk concerning the disease."). As certainty-seeking has proved to be a decisive factor for choosing presymptomatic diagnosis, it is understandable that people may accept the test, in spite of its negative emotional impact, in case of a carrier result (item 11). Let us recall that the perceived emotional burden, associated with genetic disease, was correlated in a negative and significant way with the evaluation of the genetic testing disadvantages, which suggest an important relationship between emotional and cognitive processes.

As we determined by the factorial analysis, the PADI (13 items) factorial composition is consistent with the bidimensional approach conceived between the perceived benefits and the perceived barriers of the MJD presymptomatic diagnosis. That was shown by the adequate measures of the internal consistency 
(K-R coefficients) found to the pros sub-scale and the cons dimension (.67 and .82 , respectively) of the inventory, which allows its application in investigation contexts (Nunnaly, 1978), with enlargened samples.

The PADI seems to be a useful instrument for the knowledge of the arguments that justify the decision about the early presymptomatic diagnosis. This is suggested by the percentage of the total variance accounted for by the two extracted factors $(43.87 \%)$, a satisfying value (between 40 and $50 \%$ ), which is an indicator of the adequate factor structure of a test (Snyder et al., 1996). In fact, according to Tinsley and Tinsley (1987) it is frequent that less than a half of the total variance is accounted for the extracted factors.

One of the disadvantages of self-report data is the possible influence of a social desirability bias (Tibben et al., 1997). Concern with the influence of social desirability in respondents' attitudes and opinions is acceptable mainly if we bear in mind the power of culture on the attitudes and behaviors of individuals, in relation to certain events: “... a scale built in a certain country with the help of statistic methods, is inevitably submitted to the powerful filter of "culture". This one moulds, in a direct or indirect way, the attitudes and behaviors "allowed" in face of events and is strictly connected with the genesis of emotions. Respondents who live in a cultural context point out certain questions more often than others ..." (Vaz Serra, 1994, p. 37). In statistic terms, social desirability brings about a systematic error in results, being, as such, a source of data variability (Pedhazur and Schmelkin, 1991). The answers to the PADI do not seem to be influenced by the wish of social approval, evaluated by the Social Desirability Scale (SDS), which also represents an indicator of the validity of the PADI construct.

Some studies have revealed that individuals' opinions in relations to doctors and medicine in general have influenced their motivation and adherence to health care (Andrade, 1997; Marteau et al., 1992). The more favourable are the attitudes concerning doctors and medical practice, the more positive will be subjects' evaluation of the health service they are provided with (e.g., presymptomatic diagnosis). Thus, these studies support the proposal of a relevant association between the attitudes towards doctors and medicine and the perception of the advantages of MJD genetic testing, on the one hand, and, on the other hand, of an association between attitudes concerning doctors and medicine and the perception of costs brought about by MJD presymptomatic test taking.

Additionally, certain genetic diseases, without a treatment, have been associated with the high burden (psychological, familial, marital, financial) that these families experience (Wexler, 1979, 1984). As Zagalo-Cardoso (1995) has shown, while comparing the Perceived Emotional Burden Related to Genetic Disease Scale (PEBGDS) results in three samples, concerning one disease with preventive treatment (phenilketonuria) and two incurable diseases (Down syndrome and FAP-I), the perception of burden will be the greater, the more serious will be the disease (in this case, the last two above mentioned), in terms of the absence of treatment/cure.

Thus, the PADI convergent validity was corroborated, as it was theoretically and empirically foreseen, by the correlation studies between the PADI first dimension (pros) and second dimension (cons) and the total of the Attitudes to Doctors and Medicine Questionnaire (ADMQ). And also between perceived disadvantages and the total of the PEBGDS.

In the genetic context, we would like to presume that the presymptomatic diagnosis can also be a way of reduce the emotional burden related with the stressful experience of being at risk for the disease.

Lastly, we have shown the existence of statistically significant associations between the total of the Presymptomatic Testing Acceptance Scale (PTAS) and each one of the PADI factors. Bearing in mind the convergence between the emotional and cognitive attitudinal dimensions, evaluated by the PTAS and PADI, we think they are complementing instruments. Both of them may be applied at the same time, in order to facilitate the psychosocial evaluation of the candidates to presymptomatic testing of MJD and other late genetic diseases (such as FAP-I and HD).

Owing to the theoretical and empirical importance of the separate evaluation of the subjective dimension of advantages and disadvantages of presymptomatic tests, the adequacy of the known factorial structure and the value of the internal consistency of each sub-scale, we might consider examining pros and cons separately.

As we have mentioned earlier, the Health Belief Model posit that performance of health-protective 
behaviors is associated with a higher perception of advantages, which outweigh the disadvantages associated with that action. So, we assume that the knowledge about benefits/harms beliefs can predict intentions for entering genetic testing or actual receipt of presymptomatic diagnosis.

\section{Limitations of the Study}

In interpreting the results of our study, certain limitations should be well thought-out. First, although individuals could self-refer to the study, all of them were recruited through proactive methods, according to pre-defined selection criteria (convenience sample). Second, it could be possible that those who agreed to participate in the research are, in fact, a self-selected group (Bloch et al., 1989; Codori and Brandt, 1994; Kessler, 1994; Wiggins et al., 1992), already presenting for testing discussion and actively considering presymptomatic diagnosis. We know, from subsequent findings, that approximately half of the participants took active steps toward learning about their genetic status and actually undergone genetic testing.

The main limitation of our study is that the sample is not representative for the entire population at risk for MJD. Due to the fact that MJD is a rare condition, our sample is a realistic one, in spite of its small size.

Notwithstanding these potential limitations, the present study has important applied implications.

\section{Implications for Practice}

The real outcomes of clinical interest involve the degree to which genetic screening actually increases anxiety and symptom perseverance, during the asymptomatic period between screening and disease onset (as a measure of the disadvantages), and the degree to which individuals feel that genetic testing allows them a better planning for assistance and support, during the symptomatic period (perception of positive gains).

Clinical psychologists and genetic counselors may help those considering testing to decide whether the potential costs are outweighed by its potential benefits. To fulfill this requirement, they can enable individuals to consider in detail the consequences of taking or not taking the test and may emphasize ways of fostering the person's autonomy with respect to the decision (Salkovskis et al., 1999).

The arguments to do or not to do the presymptomatic diagnosis and the subjective perception of the advantages and disadvantages of this course of action are relevant aspects to bear in mind in the elaboration of efficient psychological interventions, aiming at preventing emotional risks and at helping individuals when dealing with psychological demands of the predictive testing decisionmaking, as well as with the genetic diagnosis itself.

\section{Future Research Directions}

It is our aim to conduct longitudinal work in order: (1) to compare advantages/disadvantages perceptions prior to screening with an actual assessment of costs and benefits, after the subject has undergone screening and has been found to have the disease, and also (2) to tackle the retest reliability and validity of our measure. In the present research, the latter was unattainable, since the study was cross-sectional, so it was impossible for us to obtain any further data about the participants, who were candidates to the presymptomatic test and not yet registered in the program. Thus, we shall attempt to conduct larger scale prospective study among registrants to verify the results of our study.

We hope to use our instrument with a more broadly representative sample, in order to improve its clinical use, in what concerns the development of efficient psychological intervention strategies.

In conclusion, we hope that PADI may contribute to improve clinical answers adapted to the people at genetic risk for this disease.

\section{ACKNOWLEDGMENTS}

We wish to acknowledge all subjects for their participation in this research and we are grateful for access to at-risk individuals provided by A. Freire Gonçalves and Cristina Januário, University of Coimbra Hospitals. We express our special gratitude to Alice Rolim for her help in the translation of the original paper into English. This work has been funded by the Portuguese Science and Technology Foundation (FCT) through a fellowship to LR (PRAXIS XXI/BM/12789/97). 


\section{Appendix: Perceived Advantages and Disadvantages of Presymptomatic Testing Inventory}

INSTRUCTIONS: Next, you will find some reasons why you could decide taking or not taking the presymptomatic testing.

Signal with a cross $(x)$ in the square referred as YES or NO, depending on your agreement or disagreement with the reason which is presented in each sentence. tions.

In the end, see if you have answered all the ques-

Thank you very much for your collaboration!

Copyright 2000 by Rolim

\begin{tabular}{|c|c|c|}
\hline & YES & NO \\
\hline $\begin{array}{l}\text { 1. Taking the presymptomatic test helps me to } \\
\text { know if I should bear or not any children. }\end{array}$ & [ ] & [ ] \\
\hline $\begin{array}{l}\text { 2. Taking the presymptomatic test is not useful, } \\
\text { because there's no cure for the disease. }\end{array}$ & [ ] & [ ] \\
\hline $\begin{array}{l}\text { 3. Taking the presymptomatic test enables me } \\
\text { to inform my children about their own risk of } \\
\text { developing the disease. }\end{array}$ & [ ] & [ ] \\
\hline $\begin{array}{l}\text { 4. Taking the presymptomatic test may end the } \\
\text { tranquility of not knowing if I'll have the } \\
\text { disease. }\end{array}$ & [ ] & [ ] \\
\hline $\begin{array}{l}\text { 5. Taking the presymptomatic test may help me } \\
\text { to better plan my future. }\end{array}$ & [ ] & [ ] \\
\hline $\begin{array}{l}\text { 6. Taking the presymptomatic test may increase } \\
\text { my fear about the future. }\end{array}$ & [ ] & [ ] \\
\hline $\begin{array}{l}\text { 7. Taking the presymptomatic test may have } \\
\text { negative effects on the way I see myself (for } \\
\text { example, I may think I'm guilty about the } \\
\text { possible transmission of the disease to my } \\
\text { children). }\end{array}$ & [ ] & [ ] \\
\hline $\begin{array}{l}\text { 8. Taking the presymptomatic test may have } \\
\text { negative effects in my family life (for example, } \\
\text { increasing the worry of the wife/husband or } \\
\text { the anxiety of the children). }\end{array}$ & [ ] & [ ] \\
\hline $\begin{array}{l}\text { 9. Taking the presymptomatic test may help } \\
\text { improving psychological and social assistance } \\
\text { to all people that require it. }\end{array}$ & [ ] & [ ] \\
\hline $\begin{array}{l}\text { 10. Taking the presymptomatic test help to end } \\
\text { doubts about the state of risk concerning the } \\
\text { disease. }\end{array}$ & [ ] & [ ] \\
\hline $\begin{array}{l}\text { 11. Taking the presymptomatic test can cause } \\
\text { too much suffering, if I know that I'll have the } \\
\text { disease. }\end{array}$ & [ ] & [ ] \\
\hline $\begin{array}{l}\text { 12. Taking the presymptomatic test helps to get } \\
\text { quick and free medical assistance more easily. }\end{array}$ & [ ] & [ ] \\
\hline $\begin{array}{l}\text { 13. Taking the presymptomatic test can lead to a } \\
\text { different lifestyle (for example, giving less } \\
\text { importance to day-by-day problems). }\end{array}$ & ] & [ ] \\
\hline $\begin{array}{l}\text { 14. Taking the presymptomatic test may help me } \\
\text { to use my free time in a more balanced way } \\
\text { (for example, giving more time to family, to } \\
\text { sport, outdoor activities). }\end{array}$ & [ ] & [ ] \\
\hline
\end{tabular}

15. Taking the presymptomatic test may give rise [ ] [ ] to negative attitudes from other people (for example, employers, working colleagues, neighbors, friends).

16. Taking the presymptomatic test may lead to [ ] [ ] the detachment of close people (for example, girl/boy friend, wife/husband).

\section{REFERENCES}

Ajzen, I. (1985). From intentions to actions: A theory of planned behavior. In J. Kuhl \& J. Beckmann (Eds.), Action-control: From cognition to behavior (pp. 11-39). Heilderg, Germany: Springer.

Andrade, M. C. (1997). Abordagem Psicossocial dos Comportamentos Orientados para a Saúde [Psychosocial Approach of Health Behaviors]. Unpublished master thesis, University of Porto, Portugal.

Andrade, M. C., Zagalo-Cardoso, J. A., \& Fontaine, A. M. (1998). Custos e benefícios do diagnóstico pré-natal: Construção de uma escala de auto-avaliação [Costs and benefits of pre-natal diagnosis: Construction of a self-evaluation scale]. Progresos en Diagnóstico Prenatal, 10(9), 504-511.

Bird, T. (1999). Risks and benefits of DNA testing for neurogenetic disorders. Semin Neurol, 19(3), 253-259.

Bloch, M., Fahy, M., Fox, S., \& Hayden, M. R. (1989). Presymptomatic testing for Huntington disease: II. Demographic characteristics, life-style patterns, attitudes, and psychosocial assessments of the first fifty-one test candidates. Am J Med Genet, 32, 217-224.

Cattell, R. B. (1978). The scientific use of factor analysis in behavioral and life sciences. New York: Plenum Press.

Codori, A. M., \& Brandt, J. (1994). Psychological costs and benefits of pre-symptomatic testing for Huntington's disease. Am J Med Genet, 54, 174-184.

Coutinho, P. (1994). Doença de Machado-Joseph. Estudo clínico, patológico e epidemiológico de uma doença neurológica de origem portuguesa. Porto: Laboratórios Bial.

Craufurd, D., Kerzin-Storrar, L., Dodge, A., \& Harris, R. (1989, September 9). Uptake of pre-symptomatic testing for Huntington's disease. The Lancet, 603-605.

Crowne, D. P., \& Marlowe, D. (1960). A new scale of social desirability independent of psychopathology. J Consult Psychol, 24(4), 349-354.

Decruyenaere, M., Evers-Kiebooms, G., \& Van Den Berghe, H. (1993). Perception of pre-symptomatic testing for Huntington's disease by young women: Preferring uncertainty to certainty. J Med Genet, 30, 557-561.

Decruyenaere, M., Evers-Kiebooms, G., Boogaerts, A., Cloostermans, T., Cassiman, J.-J., Demyttenaere, et al. (1997). Non-participation in pre-symptomatic testing for Huntington's disease: Individual decision-making, personality and avoidant behavior in the family. Eur J Human Genet, $5,351-363$

Evers-Kiebooms, G. (1989). Pre-symptomatic testing in Huntington's disease. In E. H. Sikkens, B. S. et al. (Eds.), Psychosocial aspects of genetic counseling (pp. 105-118). Groningen, The Netherlands: Globe.

Evers-Kiebooms, G., \& Decruyenaere, M. (1998). Predictive testing for Huntington's disease: A challenge for persons at risk and for professionals. Patient Educ Couns, 35, 15-26.

Evers-Kiebooms, G., Swerts, A., Cassiman, J. J., \& Van Den Berghe, H. (1989). The motivation of at-risk individuals and their partners in deciding for or against predictive testing for Huntington disease. Clin Genet, 35, 29-40. 
Fishbein, M., \& Ajzen, I. (1975). Belief, attitude, intention, and behavior: An introduction to theory and research. Reading, MA: Addison-Wesley.

Fleming, M., \& Lopes, A. (2000). Saber ou não saber: Dinâmica e impasses psicológicos na doença genética [To know or not to know: Dynamic and psychological impasse in genetic disease]. Revista Portuguesa de Psicossomática, 2(1), 33-40.

Gorsuch, R. L. (1983). Factor analysis (2nd ed.). Hillsdale, NJ: Lawrence Erlbaum.

Harper, P. S. (1993). Psychosocial genetics: An emerging scientific discipline-Editorial. J Med Genet, 30(7), 537.

Harrison, J. A., Mullen, P. D., \& Green, L. W. (1992). A metaanalysis of studies of the Health Belief Model with adults. Health Educ Res: Theory \& Pract, 7(1), 107-116.

Hayden, M. R., Hewitt, J., Wasmuth, J. J., Kastelein, J. J., Langlois, S., Conneally, M., et al. (1988). A polymorphic DNA marker that represents a conserved expressed sequence in the region of the Huntington disease gene. Am J Human Genet, 42, 125131.

Hillner, B. (1996). Genetic Tests: A search for economy of scale. Am J Human Genet, 59, 287-288.

Jacopini, G. A., D'Amico, R., Frontali, M., \& Vivona, G. (1992). Attitudes of persons at risk and their partners toward presymptomatic testing. In G. Evers-Kiebooms, J. P. Fryns, J. J. Cassiman, \& H. Van Den Berghe (Eds.), Psychosocial aspects of genetic counseling (pp. 113-117). New York: Wiley-Liss.

Janis, I., \& Mann, L. (1977). Decision-making: A psychological analysis of conflict, choice and commitment. New York: Free Press.

Kawaguchi, Y. T., Okamoto, M., Taniwacki, M., Aizawa, M., Inoue, S., Katayama, H., et al. (1994). CAG expansions in a novel gene for Machado-Joseph disease in chromosome 14q32.1. Nat Genet, 8, 221-228.

Kessler, S. (1994). Pre-symptomatic testing for Huntington disease: A psychologist's view. Am J Med Genet (Neuropsychiatr Genet), 54, 161-166.

Kim, J.-O., \& Mueller, C. W. (1978). Factor analysis: Statistical methods and practical issues. Quant Appl Soc Sci Ser, 14, 7475.

Lerman, C., Croyle, R. T., Tercyak, K. P., \& Hamann, H. (2002). Genetic testing: Psychological aspects and implications. $J$ Consult Clin Psychol, 70(3), 784-797.

Marteau, T. (1990). Attitudes to doctors and medicine: The preliminary development of a new scale. Psychol Health, 4, 351386.

Marteau, T. M., Johnston, M., Kidd, J., Michie, S., \& Cook, R. (1992). Psychological Models in Predicting Uptake of Prenatal Screening. Psychol Health, 6, 13-22.

Meissen, G. J., Myers, R. H., Mastromauro, C. A., Koroshetz, M. S., Klinger, K. W., Farrer, L. A., et al. (1988). Presymptomatic testing for Huntington's disease with use of a linked DNA marker. The New England J Med, 318(9), 535542.

Motulsky, A. G. (1994). Invited editorial: Predictive genetic testing. Am J Human Genet, 55, 603-605.

Nakano, K., Dawson, D., \& Spence, A. (1972). Machado disease: A hereditary ataxia in Portuguese emigrants to Massachusetts. Neurology, 22, 49-55.

Norman, G. J., Vaughn, A. A., Roesch, S. C., Sallis, J. F., Calfas, K. J., \& Patrick, K. (2004). Development of decisional balance and self-efficacy measures for adolescent sedentary behaviors. Psychol Health, 19(5), 561575.

Nunnaly, J. C. (1978). Psychometric theory (2nd ed.). New York: McGraw-Hill Book Company.

Ogden, J. (2004). Health psychology: A textbook (3rd ed.). England: Open University Press, McGraw-Hill Education.

Paúl, M. C. (1996). Reacções Esperadas aos Resultados do Teste Pré-Sintomático: A Experiência dos programas da Doença de Huntington [Expected reactions to the results of presymptomatic testing: The experience of Huntington's Disease programs]. In J. Sequeiros (Ed.), O Teste Pré-Sintomático da Doença de Machado-Joseph [Presymptomatic testing for Machado-Joseph's Disease] (pp. 79-94). Porto: UnIGENe, IBMC.

Paúl, M. C. (1997). Genética psicossocial: o estudo das atitudes face à realização do teste preditivo da doença de MachadoJoseph [Psychosocial genetics: the study of attitudes towards undertaking presymptomatic testing for Machado-Joseph's disease]. Psicologia: Teoria, Investigação e Prática [Psychol, Theory, Res Pract], 2(2), 241-250.

Paúl, M. C., Martin, I., \& Sequeiros, J. (2000). Construção de uma escala de atitudes face ao casamento e aos filhos para estudo da adesão ao teste preditivo de doenças genéticas [Constructing a scale of attitudes towards marriage and reproduction for a study of adhesion to presymptomatic testing for hereditary diseases]. In J. Ribeiro, I. Leal, \& M. Dias (Eds.), Actas do $3^{\circ}$ Congresso Nacional de Psicologia da Saúde [Papers of the 3rd National Conference on Health Psychology] (pp. 165-171). Lisboa: I.S.P.A.

Pedhazur, E. P., \& Schmelkin, L. (1991). Measurement, design, and analysis: An integrated approach. New Jersey: Lawrence Earlbaum Associates.

Prochaska, J. O., \& DiClemente, C. C. (1983). Stages and processes of self-change of smoking: Toward an integrative model of change. J Consult Clin Psychol, 51(3), 390395.

Rolim, L. (2000). Psicologia clínica na doença de Machado-Joseph: Estudo de instrumentos de avaliação, no contexto do teste preditivo [Clinical Psychology in Machado-Joseph's Disease: A study of the instruments for evaluation in the context of presymptomatic testing]. Unpublished master thesis, University of Coimbra, Portugal.

Rolim, L. \& Zagalo-Cardoso, J. A. (in press). Escala de Aceitação do Teste Pré-Sintomático: Estudo de Validação com uma Amostra de Pessoas em Risco para a Doença de MachadoJoseph [Pre-symptomatic Testing Acceptance Scale: Validation Study with a Sample of Individuals At-Risk for Machado-Joseph Disease]

Rummel, R. J. (1970). Applied factor analysis. Evanston: Northwestern University Press.

Salkovskis, P. M., Dennis, R., \& Wroe, A. L. (1999). An experimental study of influences on the perceived likelihood of seeking genetic testing. "Nondirectiveness" may be misleading. J Psychosom Res, 47(5), 439-447.

Schwarzer, R. (1992). Self efficacy in the adoption and maintenance of health behaviors: Theoretical approaches and a new model. In R. Schwarzer (Ed.), Self efficacy: Thought control of action (pp. 217-243). Washington, DC: Hemisphere.

Sequeiros, J. (1995). Programa de teste preditivo e aconselhamento genético da doença de Machado-Joseph. Porto: UnIGENe, IBMC.

Sequeiros, J. (1996a). Aconselhamento genético e teste preditivo na doença de Machado-Joseph [Genetic counseling and predictive testing for Machado Joseph's disease]. In J. Sequeiros (Ed.), O teste preditivo da doença de Machado-Joseph [Predictive Testing for Machado Joseph's Disease] (pp. 97112). Porto: UnIGENe, IBMC.

Sequeiros, J. (1996b). Protocolo geral do programa nacional de teste preditivo e aconselhamento genético na doença de Machado-Joseph [General Protocol of the National Program for Genetic Counseling and Predictive Testing for Machado Joseph's Disease]. In J. Sequeiros (Ed.), O teste preditivo da doença de Machado-Joseph [Predictive Testing for Machado Joseph's Disease] (pp. 123-149). Porto: UnIGENe, IBMC.

Simões, A. (1987). Atitudes dos adultos face ao ensino nos CEBAS. Revista Portuguesa de Pedagogia, Ano XXI 199-19. 
Simões, A., \& Lima, M. P. (1992). Desenvolvimento do conceito de si escolar, em adultos analfabetos: um estudo longitudinal. Revista Portuguesa de Psicologia, 28, 27248.

Simões, M. (1994). Investigações no âmbito da aferição nacional do Teste das Matrizes Progressivas Coloridas de Raven (M.P.C.R.). Unpublished doctoral dissertation, University of Coimbra, Portugal.

Snyder, C. R., Sympson, S. C., Ybasco, F. C., Borders, T. F., Babyak, M. A., \& Higgins, R. L. (1996). Development and validation of the State Hope Scale. J Pers Soc Psychol, 70(2), 321-335.

Stevens, J. (1992). Applied multivariate statistics for the social sciences (2nd ed.). Hillsdale: Lawrence Erlbaum Associates, Publishers.

Streiner, D. L. (1994). Figuring our factors: The use and misuse of factor analysis. Can J Psychiatry, 39, 135-140.

Streiner, D. L., \& Norman, G. R. (1989). Health measurement scales (a practical guide to their development and use). Oxford: Oxford Medical Publications.

Taylor, S. (2002). Pre-symptomatic genetic testing: new conundrums and moral imperatives. Paper presented at Towards Humane Technologies: Biotechnology, New Media and Citizenship. An international conference exploring the social, moral and political implications of biotechnology research and commercialization (15-17 July). The University of Queensland, Ipswich, Qld.. Retrieved November 14, 2002 from: htpp://www.uq.edu.au/gsm/Confpapers/Taylor. doc

Tibben, A. (2002). Genomics and dissemination of genetic information to individuals at risk: The need for a proactive approach? Essay presented at Leids Universitair Medish Centrum, Klinische Genetica. Retrieved November 14, 2002 from: htpp://www.nwo.nl/NWOHome.nsf/pages/NWOP_ 5DPCTM\%24file/Thema3.

Tibben
Tibben, A., Timman, R., Bannink, E. C., \& Duivenvoorden, H. J. (1997). Three-year follow-up after presymptomatic testing for Huntington's disease in tested individuals and partners. Health Psychol, 16(1), 20-35.

Timmermans, D. R., \& Henneman, L. (2002). Risk perception and informed decision-making in genetic contexts. Essay presented at Department of Social Medicine, VU University Medical Center, Amsterdam.

Tinsley, H. E., \& Tinsley, D. J. (1987). Uses of factor analysis in counseling psychology research. J Counsel Psychol, 34(4), 414-424.

Tyler, A., \& Harper, P. S. (1983). Attitudes of subjects at risk and their relatives towards genetic counseling in Huntington chorea. J Med Genet, 20, 179-188.

Vaz Serra, A. (1994). Inventário de Avaliação Clínica da Depressão. Coimbra: Edição Psiquiatria Clínica.

van der Steenstraten, I. M., Tibben, A., Roos, R. A., van de Kamp, J. J., \& Niermeijer, M. F. (1994). Predictive testing for Huntington disease: Nonparticipants compared with participants in the Dutch program. Am J Human Genet, 55, 618-625.

Velicer, W. F., Hughes, S. L., Fava, J. L., Prochaska, J. O., \& DiClemente, C. C. (1995). An empirical typology of subjects within stage of change. Addict Behav, 20(3), 299-320.

Vernon, S. W., Gritz, E. R., Peterson, S. K., Perz, C. A., Marani, S., Amos, C. I., \& Braile, W. F. (1999). Intention to learn results of genetic testing for hereditary colon cancer. Cancer Epidemiol, Biomarkers \& Prev, 8, 353-360.

Wiggins, S., Whyte, P., Huggins, M., Adam, S., Theilmann, J., Bloch, M., et al. (1992). The psychological consequences of predictive testing for Huntington's disease. The New England J Med, 327(20), 1401-1405.

Zagalo-Cardoso, J. A. (1995). Aconselhamento Genético: Para uma Valorização do Paradigma Psicológico [Genetic Counseling: Towards a Valorization of the Psychological Paradigm]. Unpublished doctoral dissertation, University of Coimbra, Portugal. 